\title{
HOW ARTIFICIAL INTELLIGENCE CAN HELP THE SECTOR OF ACCOUNTING AND AUDIT DEAL WTIH COVID-19
}

\author{
Marija Mitevska, ${ }^{1}$
}

\author{
UDC $\quad 657: 004.8]: 616.98: 578.834\}-036.21$ \\ 657.6:004.8]:616.98:578.834\}-036.21
}

Student at University Goce Delcev Stip, Faculty of Economics, marija.083593@student.ugd.edu.mk

\begin{abstract}
The relationship between business activities and digital technologies is extensive and continues to grow exponentially, especially now, in the time of a global pandemic. All and any activities in various areas, have now adapted online platforms in light of social distancing measures. The COVID-19 pandemic has been compared to the Second World War, as well as the Great Depression in terms of the way it has impacted human behavior. Consequently, many changes have been made to enforce the COVID-19 safety measures, that rely on digital technologies. With this, come vast new opportunities and needs for research as well as innovation and upgrading existing systems in the field of information technology.

Artificial intelligence, also known as Al, is a general purpose technology that can be used to better efficiency, quality, safety, and solve problems faster than the traditional employee. In this paper, we will direct our attention at the problems that arise in the field of accounting and audit because of the ongoing pandemic and how they can be fixed or eliminated with the use od artificial intelligence. We will look at how the pandemic impacts the way financial reports are prepared and what changes were necessary in order to adapt and function normally and most efficiently in this time. We will also look at the possibility of eventually replacing an accountant or auditor with the system of $\mathrm{Al}$ and the risk it may pose to the traditional worker. Knowing that in a time of a pandemic, it is preferable that all and any activities that can be remote, should be completed as such. This paper will come to the conclusion that the system of artificial intelligence is of enormous use in the time of the pandemic, as well as in non extraordinary circumstances therefore, many business need to be urged to implement this kind, or a similar kind of system to help and better everyday work and improve performances. We will also see how Al can better the performance of the auditors and accountants with limiting the risk of mistakes and lowering the time needed to finish a task.
\end{abstract}

Keywords: artificial intelligence, Covid-19, implications, accounting, audit. 


\section{Introduction}

The current pandemic is an event that caught the whole world by surprise, it has been compared to the Second World War as well as the Great Depression in terms of the way it has impacted human behavior. Although, history holds memory of previous pandemics, to which we look to, to find answers and predictions of what is to come, only time will tell with certainty what the outcome of this event will be. We can only speak on the fact that the uncertainty of this pandemic lead to many problems. Everyone in every sphere of life, was not prepared to deal with this event, including accountants and auditors.

The IFRS had to come out with statements, amendments and changes that needed to be implemented in order to have an orderly financial report given out by the companies who were struggling to do so. Furthermore, many changes were made since the pandemic first started. Many companies needed to continue to work as normal as possible and that led them to resort to implementing new procedures and protocols, as well as new internal control systems. Auditors and accountants need to obtain an understanding of which controls need to be in place and how they are affecting the business, are they effective and are they giving the results that are wanted.

What is also very crucial to understand is how long it will take for a certain control to be implemented, leading to the question of will it be implemented in time to give the wanted result? We know and have established that this hurdle is real and accountants and auditors needed to adjust in order to work properly. Therefore, we will identify which problems require the most attention and how the possibility of implementing artificial intelligence into every day work in the sector of accounting and auditing might help and ease the problems that arose. We will see the distinction between automated processes and artificial intelligence, to establish how much more advanced artificial intelligence is. Artificial intelligence is still something that has yet to be widely implemented. This might be due to the fact that's it is still new, the time of implementation might be longer than wanted or whether the company that would want to implement it does not see the benefits exceeding the costs of the implementation in short term.

\section{Artificial Intelligence versus automation}

Artificial intelligence is a general purpose technology that can be used to better efficiency, quality, safety, solve problems and much more. Even though, artificial intelligence is not that new and already exists in different areas, accounting and auditing is still fairly recent in the artificial intelligence sphere. As far as companies that had openly talked about using or implementing artificial intelligence, we only know of the biggest companies, "The Big Four" in the accounting and auditing sector, to be investing and trying to implement artificial intelligence in their operational activities. There are also accounts of other smaller companies looking into and trying to be up-to-date with the newest technologies and bettering their work. [1]

The terms "artificial intelligence" and "automation" are often used interchangeably, they are associated with a software or physical robot and other machines that allow operation to be efficient and effective. Even though they are used interchangeably, there is a pretty big difference between both systems. Automation refers to making a hardware or software that is capable of doing things automatically without human intervention, however it is used for more trivial tasks to save time on repeated activities that do not require a logical think through process. Automated systems are already used everywhere, they have a single purpose, to let machines perform repetitive tasks that then, free up time for people to focus on more important and creative tasks that also require the personal touch and the judgment of a human. The end result of a automated system is an 
obedient digital robot that does not call in sick, does not take holidays and will always get the job done with minor or no mistakes at all. [2]

Artificial intelligence, on the other hand, uses data provided to the system to make human-like decisions and save time on tasks that require a higher level of a logical think through process. Artificial intelligence is designed to constantly seek patterns, learn from experience and self select appropriate responses in different situations, therefore it is a higher level of automation.

Artificial intelligence is an intelligence that is demonstrated by computers, simulating human intelligence in order to mimic human reaction, such as learning and taking action. So how does Al exactly impact the sector of accounting and audit in a time in which the pandemic severely impacted the way financial reports are made?

\section{Challenges regarding accounting and audit during the pandemic}

There is an aim to promote a thorough understanding of every aspect of the pandemic, which includes economic, social, environmental, ethical and government impact. The effects of the pandemic on the modern society will be deep and permanent and thus, calls for an in-depth, reflexive, interdisciplinary contribution in all areas of accounting, audit, business, finance and related subjects that address the responses to the COVID-19 crisis with a global perspective. Because of the pandemics complexity surrounding organization's accountability and governance was increased.[3] Even though, accounting in accountability research adapted to be sophisticated, the challenges that were posed by the COVID-19 pandemic provided a challenge and need for research in this area.[4]The pandemic heavily impacted every day activities and led to a widespread uncertainty and instability in various ways that include but were not limited to:

- $\quad$ Lowered demand on goods and services,

- $\quad$ Hardship during collecting assets from clients

- Inability to get a hold of different resources due to limitation on import and export,

- $\quad$ Less donations from nonprofit organizations

- $\quad$ Uncertainty around future assets from the government.

- $\quad$ The economic effects from the pandemic can not be considered as a subsequent event since the pandemic hit, instead there was a need for a lot of adaptations for recognition and measurement.

However, our focus will now shift to the following challenges that were caused by the pandamic and can be bettered or solved by the use of artificial intelligence.

\section{Business continuity}

It is the responsibility of the management to assess the possibility for the public sector entity to have business continuity. According to the accounting standards for the public sector, the financial statements are prepared on the assumption that the public sector entity has business continuity, which means that it will continue to operate and be able to realize funds, pay its obligations and fulfill its legal obligations in the normal course of operation in the foreseeable future. Now, because of the pandemic and its uncertainty, there might be a need for a stronger assumption about the business continuity. [5] Using artificial intelligence will allow the business entity to easily merge all information about its stability from the past, as well as use different factors that affect its stability currently, to give a rating and a better as well as stronger assumption for its continuity. This will obviously require a higher level of artificial intelligence and that will make its own decisions, its on analysis and based on those, give an end result of a stronger assumption for continuity. 
Another thing that we need to take into consideration is the amount of data about the business that needs to be provided to the software, it needs to be extensive as well as transparent. This will be very useful in assessing the business continuity, but we also cannot disregard the fact that artificial intelligence has the capability to be of upmost importance in stable and normal circumstances. If the business using that artificial intelligence feeds its software with constant data about its workings and operational activities the system can make predictions, give suggestions and assess risk factors that ease the work of accountants, as well as give a thorough report to auditors.[6] Auditors will have a higher level of trust in the artificial intelligence system and therefore save a lot of precious time not going through every report or document because the artificial intelligence system does not have a bias towards its owner i.e. company.

\section{Impairment of assets}

Public sector entities have many types of investments. Due to the impact of COVID-19, these investments may be subject to impairment. ASC topic 360, regarding impairment of PPE and intangibles with useful lives or finite lives. This means these types of assets are being amortized. These types of assets have a "trigger impairment test", in this case the trigger would be the pandemic. In that case these types of assets would need to be measured for impairment. Once the trigger is accounted for, the first step in the right direction is comparing book value with undiscounted cash flows. The challenge here is estimating the cash flow for a particular asset, if the undiscounted cash flows are less, that shows that the book value will not be recovered, so it needs to be lowered to fair value.

Another very interesting asset to look at is goodwill and indefinite lived assets. These assets do not need to be amortized, but GAAP requires annual measurements for impairment. This becomes a problem, more likely than not that specific asset is not impaired and therefore it does not require a test but, because of the current situation, this asset needs to be measured again and be written down to fair value.

How can artificial intelligence help in this situation? As previously established, artificial intelligence is a computer that learns on its own and can make decisions for itself. As we know, risks arises in the field of accounting and audit and its very crucial for those risks to be lowered to the minimum. In this case, artificial intelligence would eliminate the risks of wrongfully measuring the value for impairment, since different assets would need to be treated differently.

Another of aspect of risk to look at is, if significant mistakes are made that will give a base for wrongful decision to be made from stakeholders. The same way accounting can implement artificial intelligence to lower these risks, audit can implement this system to seek out and identify where a mistake has been made and on which bases[7] Here as well as in the business continuity, the system of artificial intelligence will need to be fed a lot of data in order to make these assumptions as well as for these assumptions to be correct, relevant and reliable. If everything is done correctly, this saves an abundance of time spent from accountants and auditors that usually analyze and assess risk at a slower rate than an artificial intelligence system. Not to mention that the level of effectiveness and efficiency will not be comparable to the level of effectiveness and efficiency of a traditional accountant or auditor.

\section{Receivables}

Public sector entities have different types of account receivables and lease receivables. Due to the increasing financial difficulty of the payer or lessee, an estimate may be required to increase the fee provision at the end of the year. Many entities issue loan applications. As a result to that many borrowers face financial difficulties due to the effects of COVID-19. So, entities will need to reassess the non-collection of loan receivables. This may lead to an increase in the provision for 
an appraisal fee or an increase in write-offs. When the principal or interest on the loan is no longer reasonably secured, the public sector entity will also cease to accrue interest income.

Governments may experience difficulties in collecting tax claims (eg income taxes, property taxes) as a result of increasing taxpayers' financial difficulties as a result of the impact of COVID-19. The relevant valuation should be re-evaluated and adjusted as necessary. Debt issued by a public sector entity on behalf of a government-owned enterprise is recognized net of related claims on the government-owned enterprise when certain conditions are met. Due to the impact of COVID19 , the entity should consider whether the receivables from the government business enterprise may be impaired and whether the net presentation requirements are still met.

Clearly the first step into bettering this operation of collecting receivables is sending out an invoice in time, therefore making it easier to pay. Optimizing receivables is rooted in being time efficient. The key factor to sending out invoices in time is not letting it be managed by humans who may or may not forget but instead of leaving it to the machines, in this case artificial intelligence to always be on time.[8] This only applies in situations where the pandemic isn't causing additional challenges that affect optimizing receivables. This does not mean that artificial intelligence cannot be useful in this sector. Taking into consideration that the pandemic has been around for sometime now, an artificial intelligence system implemented at the start or right before the pandemic hit, can have a trial period and enough data fed to let the system have time to learn and grow. In this situation the artificial intelligence system can be of great use, after it has been successfully modeled and left the trial period. The system, will be able to make its own decisions and save time on evaluation and reevaluation as well as adjustments that might need to be made, only asking for human intervention while checking to see if the system has done everything properly. Looking at the time spent on evaluation and reevaluation or making adjustments, versus the time checking for mistakes is incomparable. Therefore coming to the conclusion that investing in advance technologies can give you leverage while facing this problem.

\section{Employee benefits}

When a depression hits, it is inevitable that people are going to lose their jobs because of the inability for companies to cover their expenses. ASC topic 712 discusses contractual termination on a ongoing plan, must be communicated via a contract or union agreement, so for accruing benefits there is a need of probable and reasonable estimate. ASC topic 420 is a one time termination benefits and exit costs, which must be communicated to the employe and there must be a detailed plan by management. These two topics even though are covering the same area, they have different recognition thresholds.[9] Over the next few years, public sector entities may respond to the COVID-19 crisis in a number of ways, which may affect the obligation for defined benefit plans (eg, Temporary deviations, plan limitations). In such cases, the entity should determine whether an updated actuarial valuation is required.

Some public sector entities may reduce their workforce in the future in an effort to reduce costs. Entities recognize the benefits of termination when proven to be:

- termination of employment of an employee or group of employees;

- $\quad$ providing termination benefits as a result of the offer to encourage voluntary termination. In light of this, an implemented artificial intelligence system will allow accountants to effortlessly and accurately track the employees and their efficiency. Tracking them will allow the system of artificial intelligence to form a hierarchy list ranking from the most efficient to least efficient employee, letting managers know where cuts should be made.

Many human resources leaders say that jobs will be unrecognizable in 10 years, thanks to the adaptation of new technology. Human resources executives say that their jobs will transform due to the increase focus of people management and less administrative tasks as well as the adaptation of tools like artificial intelligence. Adapting the sector to artificial intelligence systems is 
critically important for growth as well as employee engagement and satisfaction. If this adaptation were already in place when the pandemic hit, it would have allowed entities to better manage termination and termination benefits.

\section{Challenges in audit}

Auditors check the work of the accountants to assure that everything is in order so whatever problems and challenges arise for the accountants also apply to the auditors. However, we mustn't leave out the challenges that only auditors have to face. Because of the pandemic and things working differently than usual, as well as doing some procedures while using online platforms, auditors should be on a higher alert for fraud risk, given these uncertain times. For companies that have laid off key personnel and with workforce moving out of the typical office environment, there could be a breakdown in internal control. Auditors may need to adjust procedures as necessary to help reduce any potential fraud risk that could have a material effect on the financial statements.[10] The main challenges that auditors face and that need to be adjusted to using smart software systems are:

Unable to attend inventory count: Because of the restrictions of the pandemic many things transferred to online platforms to restrict and stop the spread of the virus so auditors were unable to attend inventory account. In this case auditors had to take advantage of the technologies including camera systems with live video feeds to observe inventory counts.

Access to client records: During the pandemic accessing client books and records can present a challenge for auditors, especially in the cases where client still maintain mostly paper records. Auditors might have to obtain client prepared copy of records, but they will also need to consider the authenticity of those records and maybe perform an additional audit procedure to see if they are satisfied that the records are complete accurate and authentic.

Design implement and test of internal control: if the client of the audit is closed down and audit on site walk-throughs and tests of internal control are not a possibility auditors may need to rely on controls they may need to increase substantially of testing. Artificial intelligence will come in handy when relying on these controls and testing in order to cut down on the time which they will be performed because they will be extensive because of the lack of site walk-through and tests. When risk assessment procedures identify significant risk auditors are obligated to evaluate whether controls relevant to those significant risks are suitably designed and implemented. Since that evaluation cannot be performed through inquiry alone there is a need to determine what audit evidence can be remotely obtained or prevent and detect as well as correct material miss statement in a timely manner.[11] This can pose a big challenge, because of that, artificial intelligent systems are believed to be adequate to cater to the needs of this extensive audit procedure that is hindered by the need to be remote.

Besides these challenges, auditors will largely benefit from the system of artificial intelligence in performing tasks that require a lot of time such as performing analytical procedures, planing the audit, taking notes and cross referencing them, neatly and orderly.

\section{Out-thinking humans}

Accounting and audit is a profession and that allows adaptation to many automation processes in the past and it has been successful.[12] Therefore there's no reason to believe that adaptation to artificial intelligence is far from being our reality. In fact many big companies have already 
adapted and started using artificial intelligence to better their performances and better their efficiency. "The Big Four" companies have already invested in the system of artificial intelligence, in order to implement it in every day activities, to stay ahead on the market.[13] As time moves on and people become more and more comfortable with using artificial intelligence it will be more common for companies to use it, as well as rising the trust factor in these kinds of systems.

However our interest is now towards how is artificial intelligence able to help audit and accounting companies to deal with the pandemic that is currently underway. We have already established and seen what are some of the top problems and challenges that pose risk and difficulties from the pandemic in this field and how these problems can be fixed with more efficiency and how the risk of failure can be lowered. After all, experience from automation, computers have helped move processes in activities with bigger speed than normal manual work, there is no reason to expect less from a higher level of automation such as artificial intelligence.[16] However the system of artificial intelligence does not only hold positive and beneficial sides it also has some negativities that need to be assessed, before actually deciding on implementing such a system and going into such a big investment. As mentioned before the system can not work unless it has big amounts of data fed into it, gets through a trial and only then if it's successful it can be used in every day operational activities. Now, there are a few things to look at here, such as the amount of data needed to train the system and the possibility of the system eventually replacing the accountant or auditor.

\subsection{Information, privacy and confidentiality}

The development of artificial intelligence system is an extensive process which needs information and big data sets for training a precise algorithm for the system to work properly. This can result in ethical implications because there is a concern about the privacy of the information as well as a business confidentiality. [17]The company that will want to use this system will need to give access to a lot of information in order for the system to work and cater to the needs of the company asking for a personalized artificial intelligence system. This can raise a lot of red flags and even discourage businesses from actually going into the process of using a system and of artificial intelligence.

\subsection{Replacing humans}

Ever since the topic of using artificial intelligence in any industry started, people have been concerned with the possibility of the system outsmarting the human and eventually replacing it. People are concerned that the evolution of machines and intelligence systems such as the artificial intelligence system and many more will eventually leave no work for all the jobs that can be replaced with a robot.[19] Even though, artificial intelligence systems can hugely impact processes in the accounting and auditing sectors with bettering their efficiency, effectiveness and overall give a better result with using this tool versus not using it, the artificial intelligence system will remain just that, a tool. The basis on which this claim is made, is that accounting and auditing will always require the human factor to assess whether or not a financial data is free from material irregularities, because those irregularities, if made on purpose or are a case of fraudulent activity, were caused by humans. The human will always be needed to recognize human behavior, no matter how smart the system evolves to be, a human auditor and accountant will always be needed to have the final word. Of course others who do not embrace artificial intelligence will have a more burdensome future and they will certainly be surpassed by their colleagues who are using these kinds of systems to their advantage. Ultimately, what will be replaced is the accountants and auditors who do not use and embrace advanced technologies with the ones that do. 


\section{Conclusion}

The field of accounting an audit has already implemented technical tools to help accountants and auditors in their work and to give a reasonable assurance that the financial statements are transparent, accurate in accordance with IFSB and are free from material misstatements. With the kind of advanced technology that artificial intelligence gives, we have concluded that the traditional worker, accountant, auditor will not be replaced because of the constant and irreplacable need of human factor.

The artificial intelligence system will only better the work of accountants and auditors, make them more efficient and effective, lower time on different tasks, lower risk and overall ease their work. Therefore, they will gain leverage on their colleagues who do not embrace, implement or plan on using this kind of system. However, we mustn't forget about different risk factors or ethical implications that pose with the implementation of this system. The process of implementing the system of artificial intelligence can be a time-consuming and very expensive investment to go into. Managers, business owners, need to be aware of the time that will be spent in implementing and creating an artificial intelligence system specifically, for their business, as well as the amount of financial assets they will need to spent. Key questions that need to be posed are whether the benefits will exceed the cost of the implementation of the system long-term, does the business really need that kind of an advanced system, what kind of value will it add to the business and what is the opportunity cost of the implementation? There is no question that artificial intelligence will be of great help in every day operational activities and more so in the time of this pandemic and in a time of uncertainty, the future is technology and innovation. Those who are a step ahead and keep up to date with the newest trends will always come on top in stable circumstances and be prepared for the next shock like the COVID-19 pandemic is right now.

\section{References}

1.Covid-19 Artificial Intelligence." Www.coe.int, www.coe.int/en/web/portal/covid-19-artificial-intelligence. Accessed 15 April 2021.

2.Vargo, Deedra, et al. "Digital Technology Use during COVID - 19 Pandemic: A Rapid Review." Human Behavior and Emerging Technologies, 28 Dec. 2020, 10.1002/hbe2.242. Accesed 15 April 2021.

3. "GAAP Dynamics." Revolution.gaapdynamics.com, revolution.gaapdynamics.com/collections/covid-19-course-collection. Accessed 20 May 2021.

4."Al - What Does It Mean for the Future of Accountancy?" Www.icaew.com, www.icaew.com/technical/technology/tech-faculty/ai-what-does-it-mean-for-the-future-of-accountancy. Accessed 22 May 2021.

5."Consequences of COVID-19: Potential Auditing Challenges." Future.aicpa.org, future.aicpa.org/resources/download/consequences-of-covid-19-potential-auditing-challenges. Accesed 22 May 2021.

6."Challenges in Audit with Pandemic - Google Search." Www.google.com, www.google.com/search?q=challenges+in+audit+with+pandemic\&ie=UTF-8\&oe=UTF-8\&hl=enus\&client=safari. Accessed 24 May 2021.

7.Munoko, Ivy, et al. "The Ethical Implications of Using Artificial Intelligence in Auditing." Journal of Business Ethics, 8 Jan. 2020, 10.1007/s10551-019-04407-1. Accessed 27 May 2021. 
8.Sharp, Julian. Exam Ref Ai-900 Microsoft Azure Ai Fundamentals. S.L., Microsoft, 2021

9. BDO (2020)- "Covid-19: Financial Reporting Implications For The Public Sector"

10. EY (2020)- "IFRS accounting considerations of the coronavirus outbreak"

11. BDO IFR Advisory Limited (2020)- "Potential Effects Of The Coronavirus Outbreak On 31December 2019 Year End Financial Reporting"

12. BDO IFR Advisory Limited (2020)- "Potential Effects Of The Coronavirus Outbreak On 2020 Reporting Periods And Onward"

13. BDO IFR Advisory Limited (2020)- "Impairment Implications Of Covid-19 (IFRS 9 Financial Instruments)"

14. Marshall, John C, et al. "A Minimal Common Outcome Measure Set for COVID-19 Clinical Research." The Lancet Infectious Diseases, vol. 20, no. 8, Aug. 2020, pp. e192-e197, www.who.int/docs/default-KMPG Sri Lanka (2020)- "COVID-19 Financial Reporting Implications- Are Assets Being Carried at Appropriate Amounts?"

15. The Financial Reporting Implications of COVID-19." IFAC, 13 Apr. 2020, www.ifac.org/knowledge-gateway/supporting-international-standards/discussion/financial-reporting-implications-covid-19.

16. KMPG Sri Lanka (2020)- "COVID-19 Financial Reporting Implications- Interim Reporting Adjusting or Non Adjusting Event Going Concern Considerations?"

17. "Summary of Covid-19 Financial Reporting Considerations." IFAC, 20 May 2020, www.ifac.org/knowledge-gateway/supporting-international-standards/discussion/summarycovid-19-financial-reporting-considerations.

18. PwC- Tony Debell and Vikash Kalidas (2020)- "Accounting implications of the effects of coronavirus"

19."AI Will Not Replace Auditors, but Auditors Using AI Will Replace Those Not Using Al." Mind-

Bridge, 2 Mar. 2018, www.mindbridge.ai/blog/ai-will-not-replace-auditors-but-auditors-using-aiwill-replace-those-not-using-ai/. Accessed 27 May 2021. 